\title{
A BIOLOGICAL DIFFERENCE BETWEEN NATURAL SEA WATERS
}

\author{
By Douglas P. Wilson, D.Sc., F.R.P.S. \\ Zoologist at the Plymouth Laboratory
}

(Plates I and II)

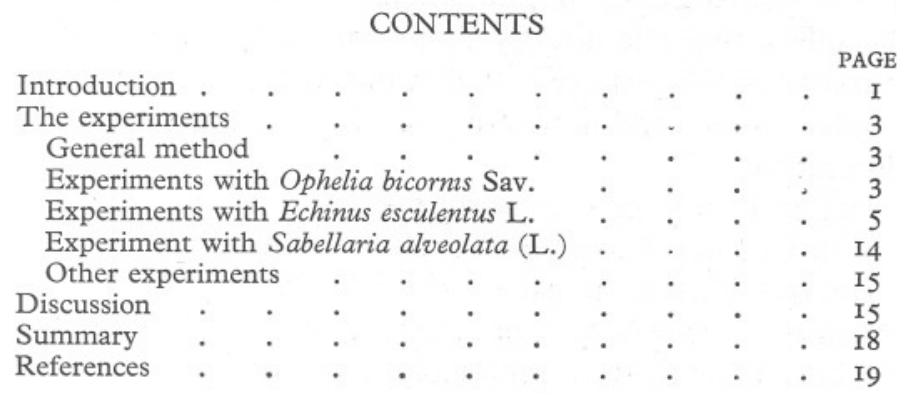

\section{INTRODUCTION}

The work of F. S. Russell on plankton animals as indicators of different water masses, particularly the species Sagitta setosa J. Müller and S. elegans Verrill, and of Atkins, Harvey and Cooper on plant nutrients, have pointed the conclusion that the water in the English Channel, in the neighbourhood of Plymouth, was consistently richer in nutrients and plankton in the 5 or 6 years prior to about 1930 than it has been at any time since. (See Russell, I935, I936 $a$, I939; Cooper, I938; Armstrong \& Harvey, 1950; Harvey, 1950.) The comparative infertility of the sea in this area in the 1930's, and until the present time, has been shown not only by the low winter phosphate maximum, and by the sparse plankton characterized by the presence of S. setosa, but also by the reduced numbers of young fishes surviving their early larval stages after the summer spawning (Russell, 1939).

It was during the I930's that I experienced much frustration in numerous attempts to rear the larvae of various species of polychaetes. It may be that the species concerned would in any event have proved difficult, but the meagre results obtained for energy expended, especially when compared with the easier successes of the later years of the I920's, gradually led to a suspicion that there might be another explanation. As it became clearer, from the work of Russell and Cooper, that local planktonic and hydrographic conditions had changed, it occurred to me that, quite apart from considerations of nutrients and plankton food, the local sea water which I was using for my work might itself be a less favourable medium for developing eggs and larvae than formerly. It seemed at least possible that some species would develop more readily in 
elegans than in setosa water, and perhaps vice versa. Before 1930 the water used for rearing would very likely have been elegans water, while after that date setosa water was probably employed. All water used for rearing had been passed through Berkefeld filter candles so that plankton organisms in the water had been removed, any necessary food having been provided from artificial cultures, generally of the diatom Nitzschia. Thus if setosa water was less favourable than elegans water for eggs and larvae, it was not due to the contained plankton. It might be that setosa water lacked some vital substance, or alternatively contained in minute amount something harmful to certain species. The effect might be directly on the larvae themselves, or it might be on the maturation of the germ cells so that in some species eggs produced and fertilized under setosa conditions are less viable than those matured in an elegans environment.

This possibility had become apparent even before 1939, and on discussing the matter with Dr Cooper that year I found that he also, but from a different direction, was approaching similar conclusions. We considered the practicability of obtaining elegans water from the westward, but before this could be done war broke out and made it impossible, and it was not until fairly recently that the two kinds of water could actually be tested.

The first tests were made in the summer of 1948 . I was at that time engaged in experimenting with larvae of the small polychaete Ophelia bicornis. Usually there is little difficulty in rearing this species, but that particular summer several cultures had unaccountably failed. The question of the water was again raised, and on his next cruise to the westward Dr Cooper very kindly obtained some elegans water for me. Using this water, exceptionally fine rearings were obtained; at the same time some direct comparative tests of this elegans water with our ordinary 'Outside' water were also made. The results were so encouraging (Exps. I and 2, pp. 3-5) that the following spring, and again the next year, more extensive tests were undertaken, using plutei of Echinus esculentus which are specially sensitive to cultural conditions. The larvae of another polychaete, Sabellaria alveolata, were also tested.

Before detailing the experiments the names adopted for the waters must be explained. It is thought better to refer to them by their location, for although in these experiments the water from the Celtic sea (definition in Cooper \& Vaux, 1949, p. 750) always contained typical elegans plankton, and the Outside water consistently contained a very sparse zooplankton (a characteristic of setosa water) in a further series this might not be so. The plankton was taken, usually at the same time as the water, with a $2 \mathrm{~m}$. stramin ring-trawl. Outside water derives its name from the fact that it is got off Plymouth, outside the breakwater and well out to sea, often from beyond the Eddystone.

For much helpful discussion I wish to thank especially Mr F. S. Russell, Dr H. W. Harvey and Dr L. H. N. Cooper. Dr Cooper and Mr F. A. J. Armstrong have given invaluable help technically; they collected, often under 
trying conditions, most of the samples of water tested, and they are responsible for the water analyses and other hydrographical data given in this paper. The plankton was examined by Mr P. G. Corbin who kindly supplied the descriptions.

\section{THE EXPERIMENTS}

\section{General Method}

All glassware was cleaned with warm concentrated sulphuric acid and thoroughly washed. Throughout, special attention was given to cleanliness and the avoidance of contamination. Care was taken to treat both sides of an experiment alike. All vessels containing water and larvae undergoing comparative tests were kept side by side under identical lighting and temperature conditions. All waters were filtered through Berkefeld filter candles. In the earlier experiments the test vessels were glass finger bowls of diameter approximately $\mathrm{I} 2.5 \mathrm{~cm}$. and total capacity 500 c.c. They were filled to just over half capacity. In the I950 experiments, with Echinus esculentus, crystallizing dishes $7 \mathrm{~cm}$. in diameter and of approximately I60 c.c. total capacity were used. They were about two-thirds filled, water levels being equal in all dishes in any one experiment.

\section{Experiments with Ophelia bicornis Sav.}

Fertilizations were made by slitting open mature worms to obtain eggs and sperms. The fertilized eggs were then divided equally into two portions, each of which was thoroughly washed with one of the waters being tested. After I6-20 hr. surface-swimming larvae were poured off into new bowls to separate them from undeveloped eggs, or abnormal larvae which had not swum up. Additional water was added to the new bowls and the levels equalized.

\section{Experiment I}

Celtic sea water collected from the sea surface by means of a wooden bucket.

Position: $50^{\circ} 00^{\prime}$ N., $7^{\circ}$ I0' W. Sounding: I Io m.

Date: 30. vi. 48 . Time: 04.40 hr. G.M.T.

Ship: R.V. Sabella, with Dr L. H. N. Cooper.

Conditions: rough sea and heavy confused swell, in spite of which salinity at $0.5 \mathrm{~m}$. was greater by $0.09 \%$ than at $5 \mathrm{~m}$.

Physical and chemical observations:

$\begin{array}{ccc}\begin{array}{c}\text { Depth } \\ \text { (m.) }\end{array} & \begin{array}{c}\text { Temp. } \\ \left({ }^{\circ} \mathrm{C} .\right)\end{array} & \begin{array}{c}\text { Salinity } \\ (\%)\end{array} \\ 0.5 & 13.63 & 35.21 \\ 5 & 13.59 & 35.12 \\ 50-107 & 9.83 & 35.22 \\ \begin{array}{c}\text { Integral mean of } \\ \text { water column }\end{array} & - & -\end{array}$

\begin{tabular}{ccc}
\multicolumn{3}{c}{ Phosphorus $\left(\mathrm{mg}\right.$.-atom $/ \mathrm{m.}^{3}$ ) } \\
$\overbrace{\text { Total }}^{\text {Inorganic }}$ & Organic \\
- & 0.06 & - \\
0.36 & 0.04 & 0.32 \\
0.70 & $0.44-0.5 \mathrm{I}$ & 0.23 \\
0.58 & 0.33 & 0.25
\end{tabular}

The Outside water was from the ordinary laboratory stock, recently collected from the sea surface well offshore from Plymouth. Very little plankton had been present in the area throughout June and early July. 
On the way home from the Celtic sea, hydrographical observations were made at station $\mathrm{E}$ I but no water was collected for the present work.

Position: E I, $50^{\circ} 02^{\prime} \mathrm{N} ., 4^{\circ} 22^{\prime} \mathrm{W}$.

Date: I. vii. 48.

$\begin{array}{cccccc}\begin{array}{c}\text { Depth } \\ (\mathrm{m} .)\end{array} & \text { Temp. } & \begin{array}{c}\text { Salinity } \\ (\%)\end{array} & \overbrace{}^{\circ} \text { Total } & \text { Inorganic } & \text { Organic } \\ 0.5 & \text { I3.55 } & 35.34 & 0.39 & 0.04 & 0.35 \\ 5 & \text { I3.53 } & 35.34 & 0.39 & 0.01 & 0.38 \\ 50-70 & \text { II.50 } & 35.37 & 0.53 & 0.31 & 0.22 \\ \begin{array}{c}\text { Integral mean of } \\ \text { water column }\end{array} & - & - & 0.52 & 0.23 & 0.29\end{array}$

The Channel was more saline by about $0.2 \%$, otherwise the two stations differed only in the bottom water which in the Celtic sea was colder and richer in inorganic and consequently in total phosphorus. The phosphorus results do not suggest that minimum organic production had been markedly different at the two stations.

The fertilizations of Ophelia were made in Celtic water on 8. vii. 48. Three separate fertilizations were made, using three females for each. One male was used to fertilize all the eggs. Each fertilization was immediately divided equally between the two kinds of water and treated as already described.

Results are summarized in Table I. They are positive in favour of Celtic water. After about a week there were many more abnormalities in Outside than in Celtic water. Prototrochal cilia were lost, without proper meta-

TABle I. EXP. I. Fertilizations of OPhelia bicornis MADE ON 8 JULY 1948

Fertilization no. I $\quad$ Fertilization no. $2 \quad$ Fertilization no. 3 Condition of larvae in Condition of larvae in Condition of larvae in

Celtic water Outside water $\overbrace{\text { Celtic water Outside water Celtic water Outside water }}^{\text {Cuts }}$ I5. vii. 48 Very good Good Very good Good Very good Good

19. vii. 48 Good Fairly good Good Fairly good Good Fairly good

24. vii. 48 Good

28. vii. 48 Fairly good, Poor Very good majority majority Good Fair Very good Fair alive dead Good, Poor, Very good, Poor, all living many dead all living many dead

morphosis, earlier in Outside than in Celtic water. In Outside water very many larvae stuck together in large masses; they did so hardly at all in Celtic water. Larvae in Celtic water outlived those in Outside water.

\section{Experiment 2.}

Particulars of waters as for Exp. I.

The fertilizations of Ophelia were made in Celtic water on I2. vii. 48 . Three separate fertilizations were made, using one female for each. One male was used for all three. Each fertilization was immediately divided into both kinds of water, as already described.

Results are summarized in Table II. They are positive in favour of Celtic water. On I7. vii. 48 large numbers of larvae in all three bowls of Outside 
water were stuck together in very big masses, but larvae in Celtic water were not so massed together and appeared to be much healthier. On this date considerable numbers of larvae were removed from two bowls of Celtic water (Fertilizations 5 and 6) to supply experiments with which this paper is not concerned. After this date these two bowls therefore contained fewer larvae than the corresponding bowls of Outside water.

\begin{tabular}{|c|c|c|c|c|c|c|}
\hline \multirow{4}{*}{$\begin{array}{l}\text { I7.vii. } 48 \\
24 . \text { vii. } 48 \\
26 . \text { vii. } 48\end{array}$} & \multicolumn{2}{|c|}{$\begin{array}{l}\text { Fertilization no. } 4 \\
\text { Condition of larvae in }\end{array}$} & \multicolumn{2}{|c|}{$\begin{array}{l}\text { Fertilization no. } 5 \\
\text { Condition of larvae in }\end{array}$} & \multicolumn{2}{|c|}{$\begin{array}{l}\text { Fertilization no. } 6 \\
\text { Condition of larvae in }\end{array}$} \\
\hline & Celtic water & Outside water & Celtic water & Outside water & Celtic water & Outside water \\
\hline & Very good & Good & Very good & Good & Very good & Good \\
\hline & & & Very good & Good & Good & $\begin{array}{l}\text { Very poor, } \\
\text { many dead }\end{array}$ \\
\hline 28. vii. 48 & Very good & Fairly good & Good & Fair & Good & $\begin{array}{c}\text { Almost all } \\
\text { dead }\end{array}$ \\
\hline
\end{tabular}

Experiments with Echinus esculentus $L$.

Recently trawled urchins were used, if possible immediately after trawling, or within a day or two. For each experiment one ripe female and one ripe male were selected by microscopic examination of the gonads after removal of the oral portion of the test. The aboral surfaces were then well rinsed and the inverted urchins spawned into beakers of filtered sea water, either Outside or Celtic. The fertilized eggs were at once divided equally between two beakers and thoroughly washed with six to eight changes, one of Outside water and the other of Celtic water. From each, after thorough stirring to distribute the eggs evenly, equal volumes were removed in a glass dipper to vessels already containing equal volumes of the waters to be tested. Thus very nearly the same number of eggs was added to all vessels. Three or more vessels of each kind of water were tested in a single experiment. After $24 \mathrm{hr}$. swimming blastulae were poured off into a second set of vessels, to separate them from undeveloped or abnormally developing eggs on the bottom, except in the 1950 experiments when this was not necessary. The water-levels in the second set of vessels were equalized.

\section{Experiment 3}

Celtic sea water collected from the sea surface by means of a wooden bucket.

Position: $50^{\circ} 36^{\prime}$ N., $8^{\circ} 04^{\prime}$ W. (over Labadie Bank). Sounding: $70 \mathrm{~m}$.

Date: ro. iii. 49. Time: or.r 5 hr.

Ship: R.V. Sabella with Dr L. H. N. Cooper.

Conditions: heavy swell immediately following moderate gale (Beaufort Force 7). Vertical mixing should have been considerable.

Plankton : night haul rich with abundant Sagitta elegans, large Aglantha, Euphausians, etc. No sign of phytoplankton. 
Physical and chemical observations were:

$\begin{array}{cccccc}\begin{array}{c}\text { Depth } \\ (\mathrm{m} .)\end{array} & \begin{array}{c}\text { Temp. } \\ \left({ }^{\circ} \mathrm{C} .\right)\end{array} & \begin{array}{c}\text { Salinity } \\ (\%)\end{array} & \overbrace{\text { Total }} & \text { Inorganic } & \text { Organic } \\ 5 & 9.95 & 35.24 & 0.69 & 0.51 & 0.18 \\ 25 & 9.98 & 35.23 & 0.76 & 0.50 & 0.26 \\ 60 & 9.98 & 35.23 & 0.79 & 0.49 & 0.30 \\ \text { Integral mean of } & - & - & 0.76 & 0.50 & 0.26 \\ \text { water column } & & & & & \end{array}$

Outside sea water collected from the sea surface by means of a wooden bucket by M.F.V. Sula during third week of March 1949; exact position unknown. Ordinary laboratory routine collection in glass carboys which had contained sulphuric acid and had previously been well washed out.

Plankton (routine daylight haul 2 miles east of Eddystone) on 2I. iii. 49, very, very sparse, hardly any zooplankton, one Sagitta setosa present. No sign of phytoplankton.

Physical and chemical observations at station E I were:

\begin{tabular}{|c|c|c|c|c|c|c|c|c|c|c|}
\hline \multirow{3}{*}{$\underset{\text { (m.) }}{\text { Depth }}$} & & & & & \multicolumn{6}{|c|}{ Phosphorus (mg.-atom $/ \mathrm{m}^{3}$ ) } \\
\hline & \multicolumn{2}{|c|}{ Temp. $\left({ }^{\circ} \mathrm{C}.\right)$} & \multicolumn{2}{|c|}{ Salinity $(\%)$} & \multicolumn{2}{|c|}{ Total } & \multicolumn{2}{|c|}{ Inorganic } & \multicolumn{2}{|c|}{ Organic } \\
\hline & I. iii. 49 & I3. iv. 49 & I. iii. 49 & I3. iv. 49 & I. iii. 49 & I3. iv. 49 & I. iii. 49 & I3. iv. 49 & I. iii. 49 & I3. iv. 49 \\
\hline Surface & IO.I & - & $35 \cdot 38$ & - & 0.7 & - & 0.43 & - & 0.08 & - \\
\hline 0.5 & - & 9.90 & - & $35 \cdot 37$ & - & 0.53 & - & 0.28 & - & 0.25 \\
\hline $5_{-70}^{5}$ & $\begin{array}{l}10.06 \\
10.02\end{array}$ & $9 \cdot 88$ & $\begin{array}{l}35 \cdot 35 \\
35 \cdot 35\end{array}$ & $35 \cdot 38$ & $0.4 I$ & 0.47 & 0.38 & 0.31 & 0.03 & 0.16 \\
\hline $\begin{array}{l}\text { Integral mean } \\
\text { of water } \\
\text { column }\end{array}$ & 10.03 & 9.87 & $\begin{array}{l}35 \cdot 35 \\
35 \cdot 35\end{array}$ & $\begin{array}{l}35 \cdot 30 \\
35 \cdot 29\end{array}$ & $\begin{array}{l}0.44 \\
0.44\end{array}$ & $\begin{array}{l}0.45 \\
0.47\end{array}$ & $\begin{array}{l}0.4 \mathrm{I} \\
0.39\end{array}$ & $\begin{array}{l}0.32 \\
0.31\end{array}$ & $\begin{array}{l}0.04 \\
0.05\end{array}$ & $\begin{array}{l}0.13 \\
0.16\end{array}$ \\
\hline
\end{tabular}

The Celtic water had evidently been much richer in total phosphorus and by IO. iii there had been more conversion to organic phosphorus than had taken place a month later in the Channel. Again the Channel water was more saline.

An Echinus esculentus fertilization was made in Celtic water on 24.iii. 49. Three bowls of each kind of water were tested.

Results are summarized in Table III. They are positive in favour of Celtic water, although the larvae in this water were the first to show shrinkage of flesh on the arms, the skeletal rods protruding uncovered (29. iii. 49). Regeneration of the arms of many larvae took place after 3I. iii. 49. There was no regeneration in Outside water, although the bowls were kept until 20. iv. 49.

\section{Experiment 4.}

Particulars of waters, etc., as for Exp. 3, but another pair of E. esculentus used for the fertilization, which was made in Outside water. Three finger bowls of each kind of water were tested.

Results are summarized in Table IV. They are positive in favour of Celtic water, but this fertilization did not do as well as that of Exp. 3. On 28. iii. 49 the larvae in all three bowls of Celtic water were clearly healthier than those in Outside water.

\section{Experiment 5 .}

Particulars of waters, etc., as for Exp. 3 .

E. esculentus fertilization made in Celtic water on 30. iii. 49. Four bowls of 
each kind of water were tested and, in addition, there were four bowls of a mixture of approximately equal volumes of both waters. Two bowls of each series were given food (Nitzschia and an autotrophic flagellate).

Results are summarized in Table V. They are positive in favour of Celtic water. The Mixed water was almost as good as the Celtic. Feeding made no

\title{
Table III. Exp. 3. Fertilization of EChinus esculentus MADE ON 24 MARCH I949
}

\author{
Condition of larvae in Celtic water \\ (bowls $I-3$ ) \\ Condition of larvae in Outside water \\ (bowls 4-6)
}

26. iii. 49 Many at surface, few on bottom

28. iii. 49 Most at surface, some in mid-water, few on bottom

29. iii. 49 Bowl I : about one-third at surface, a few in mid-water, most on bottom. Bowls 2 and 3 : most at surface, few in mid-water, about one-third on bottom. Few dead in all three bowls. In most of the living the flesh of the arms shrinking away

30. iii. 49 Few at surface, most on bottom

31. iii. 49 All on or near bottom, unhealthy with shortened arms, some dead

4. iv. 49 Many at surface or in mid-water, most at bottom, generally short-armed but some long-armed. Some dead

6. iv. 49 Numbers at surface or in mid-water, many on bottom, some dead. Swimming larvae with long slender arms, on bottom many with short arms, or with none

Few at surface, many on bottom

Some at surface and in mid-water but most on bottom, some dying

Bowl 4: about one-half mid-water to surface, remainder on bottom. Bowls 5 and 6: fair number between bottom and surface, most on bottom. Many dead in all three bowls. In the living the arms are generally normal. A little shrinkage of flesh

Few at surface, most on bottom

All on or near bottom, unhealthy with shortened arms, many dead

All on bottom, majority dead. Living abnormal, with very short arms or none at all

All on bottom, a few with short arms, most with none, bodies generally shrunken and abnormal. Majority dead

Table IV. Exp. 4. Fertilization of EChinus esculentus MADE ON 24 MARCH I949

Condition of larvae in Celtic water (bowls I-3)

26. iii. 49 Most at surface, few on bottom

28. iii. 49 Most at surface, some in mid-water, few or none on bottom. A few larvae abnormal

29. iii. 49 Many at surface, few in mid-water, most on bottom. Flesh of arms shrinking from skeletal rods

30. iii. 49 All in poor condition
Condition of larvae in Outside water (bowls 4-6)

Some at surface, most on bottom

Many at surface and in mid-water, a considerable number on bottom. Many abnormal

Some at surface, some in mid-water, most on bottom. Flesh of arms shrinking from skeletal rods

All in poor condition

appreciable difference and did not help the larvae in Outside water. On 6.iv. 49 the $\mathrm{pH}$ was the same for all bowls; it did not differ from normal sea water. There was some regeneration of arms of plutei in Outside water after 9. iv. 49, but in only one bowl did this progress to any extent. In this one bowl there were fair numbers of good plutei on 20. iv. 49 when the experiment was ended. Conditions at this time varied from bowl to bowl, rather irrespective of the kind of water.

Larvae from Celtic and Outside water were photographed on 7. iv. 50 (Pl. I, figs. I, 2). 


\section{Table V. Exp. 5. Fertilization of Echinus esculentus MADE ON 30 MARCH I949}

Condition of larvae

in Celtic water

(bowls I-4)

2. iv. 49 Many near surface, few near bottom

3. iv. 49 Many swimming, marked concentration near surface. Many on bottom

5. iv. 49 Many swimming, some concentration near surface. On bottom some abnormal

6. iv. 49 Many normal plutei concentrating near surface. On bottom most becoming abnormal. None dead

9. iv. 49 Many normal plutei swimming. Most on bottom abnormal

II. iv. 49 Many normal plutei swimming. Most on bottom abnormal
Condition of larvae

in Mixed water

(bowls 5-8)

Many near surface, few near bottom

Many swimming, some concentration near surface. Many on bottom

Many swimming, some concentration near surface. On bottom some abnormal

Many normal plutei concentrating near surface. On bottom most becoming abnormal. None dead Many normal plutei swimming. Most on bottom abnormal

Many normal plutei swimming. Most on bottom abnormal
Condition of larvae

in Outside water

(bowls 9-12)

Many near surface, few near bottom

Many swimming, some concentration near surface. Many on bottom

Few swimming, most on bottom becoming abnormal

Very few swimming and all abnormal, those on bottom often very shrunken; some dead

Very few swimming and all abnormal. Most on bottom very abnormal or dead

Fair number swimming, regenerating arms. Most on bottom very abnormal

\section{Table VI. Exp. 6. Fertilization of EChinUs ESCUlENTUS MADE ON 2I APRIL I949}

Condition of larvae in Celtic water

$\overbrace{\begin{array}{c}\text { Bowls I-3, many } \\ \text { larvae per bowl }\end{array}}^{\begin{array}{c}\text { Bowls 4-6, few } \\ \text { larvae per bowl }\end{array}}$

25. iv. 49 Many on bottom

27. iv. 49 Very few swimming, most on bottom. All abnormal, many dead

3. v. 49 All dead

\section{Experiment 6.}

Condition of larvae in Outside water

$\overbrace{\begin{array}{c}\text { Bowls } 7-9, \text { many } \\ \text { larvae per bowl }\end{array}}^{\begin{array}{c}\text { Bowls ro-12, few } \\ \text { larvae per bowl }\end{array}}$

Some normal plutei swimming. Some abnormal and some dead on bottom
Few on bottom

Few swimming, most on bottom. All abnormal, many dead plutei swim On bottom some abnormal, many dead

Bowl 7, all dead. Bowl 8, most dead, a few very abnormal living. Bowl 9, a few swimming, abnormal. Most on bottom, very abnormal, half of them dead
Some normal plutei swimming, more than in Celtic water. On bottom some dead, some abnormal, fewer than in Celtic water

A few normal and more abnormal plutei swimming. A few dead

\section{Particulars of Celtic water as for Exp. 3 .}

Outside water collected (from sea surface with wooden bucket) by $\mathrm{Mr}$ F. A. J. Armstrong in M.F.V. Sula, 13. iv. 49. 
Position: EI.

Plankton: daylight haul; very, very sparse, hardly any zooplankton except pilchard eggs in some numbers, one Sagitta setosa present. No sign of phytoplankton.

For physical and chemical properties see under Exp. 3 .

After the previous experiments the Berkefeld filter candles had been cleaned and re-sterilized. That previously used for filtering Celtic water was here used for Outside water, and vice versa.

Echinus esculentus fertilization made in Celtic water on 21.iv. 49. Four bowls of each kind of water were tested; in two bowls larvae were numerous, in two few in number.

Results are summarized in Table VI. They are negative. The fresh Outside water was slightly better than the 6-week-old Celtic water, but neither was good. Larvae did better when there were relatively few per bowl.

\section{Experiment 7}

Celtic sea water collected from $20 \mathrm{~m}$. by means of the pump.

Position: $49^{\circ} 44^{\prime}$ N., $8^{\circ} 50^{\prime}$ W. Sounding: $89 \mathrm{~m}$.

Date: 3 . v. 49 . Time: 20.50 hr. G.M.T.

Ship: R.V. Sabella with Dr L. H. N. Cooper.

Conditions: moderate sea, wind force 5 .

Plankton: night haul rich with numerous small Aglantha, Tomopteris and young fish; very abundant plutei, one Sagitta serratodentata; Phaeocystis abundant. No Sagitta elegans.

Physical and chemical observations:

$\begin{array}{ccc}\begin{array}{c}\text { Depth } \\ \text { (m.) }\end{array} & \begin{array}{c}\text { Temp. } \\ \left({ }^{\circ} \mathrm{C} .\right)\end{array} & \begin{array}{c}\text { Salinity } \\ (\% \circ)\end{array} \\ 0 & \text { II } \cdot 48 & 35 \cdot 37 \\ 5 & \text { II.50 } & 35.35 \\ 20 & \text { II.50 } & 35.36 \\ 40 & \text { II. } 8 & 35.37 \\ 80 & \text { I0.82 } & 35 \cdot 38 \\ \text { Integral mean of } & - & - \\ \text { water column } & & \end{array}$

\begin{tabular}{|c|c|c|}
\hline \multicolumn{3}{|c|}{ Phosphorus (mg.-atom/m. ${ }^{3}$ ) } \\
\hline Total & Inorganic & Organic \\
\hline 0.37 & O.10 & 0.27 \\
\hline 0.33 & 0.17 & $\begin{array}{l}0.16 \\
0.22\end{array}$ \\
\hline 0.34 & $\begin{array}{l}0.12 \\
0.15\end{array}$ & $\begin{array}{l}0.22 \\
0.30\end{array}$ \\
\hline $\begin{array}{l}0.45 \\
0.63\end{array}$ & $\begin{array}{l}0.15 \\
0.40\end{array}$ & 0.23 \\
\hline 0.46 & 0.23 & 0.23 \\
\hline
\end{tabular}

Outside sea water collected from sea surface with wooden bucket.

Position: L 5, $50^{\circ} \mathrm{II}^{\prime}$ N., $4^{\circ} \mathrm{I} 8^{\prime} \mathrm{W}$. Sounding: $68 \mathrm{~m}$.

Date: 2. v. 49 . Time: I0.20 hr. G.M.T.

Ship: M.F.V. Sula with Mr F. A. J. Armstrong.

Conditions: fresh north-west wind, sea moderate but increasing.

Plankton: daylight haul, very, very sparse except for pilchard eggs which were abundant. Four Sagitta setosa. No sign of phytoplankton.

Physical and chemical observations:

$\begin{array}{ccc}\begin{array}{c}\text { Depth } \\ \text { (m.) }\end{array} & \begin{array}{c}\text { Temp. } \\ \left({ }^{\circ} \mathrm{C} .\right)\end{array} & \begin{array}{c}\text { Salinity } \\ (\% \circ)\end{array} \\ 5 & 10 \cdot 23 & 35 \cdot 26 \\ \text { 10 } & 10 \cdot 17 & 35 \cdot 27 \\ 25 & 10 \cdot 08 & 35 \cdot 28 \\ 50 & 10 \cdot 08 & 35 \cdot 31 \\ \begin{array}{c}\text { Integral mean of } \\ \text { water column }\end{array} & - & -\end{array}$

$\begin{array}{lcc}\text { Phosphorus }\left(\mathrm{mg} . \text {-atom } / \mathrm{m}^{3} \text { ) }\right. \\ \overbrace{\text { Total }}^{\text {Inorganic }} & \begin{array}{c}\text { Organic } \\ 0.37\end{array} & 0.22 \\ 0.38 & 0.15 & 0.23 \\ 0.42 & 0.22 & 0.20 \\ 0.51 & 0.26 & 0.25 \\ 0.43 & 0.21 & 0.22\end{array}$

The Channel water was less saline but there was nothing to choose between the waters in terms of phosphorus content. 
Berkefeld filter candles again cleaned and changed over.

Echinus esculentus fertilization made on 6. v. 49. Six bowls of each kind of water were tested; in three bowls larvae were numerous, in three, few in number.

Results are summarized in Table VII. They are negative; there was no observable difference between comparable bowls of larvae and in neither water was a satisfactory rearing obtained. Bowls with few larvae did a little better than bowls with many. Regeneration of the arms of some plutei took place in both waters after I4. v. 49 .

\section{Table VII. Exp. 7. Fertilization of Echinus esculentus MADE ON 6 MAY I949}

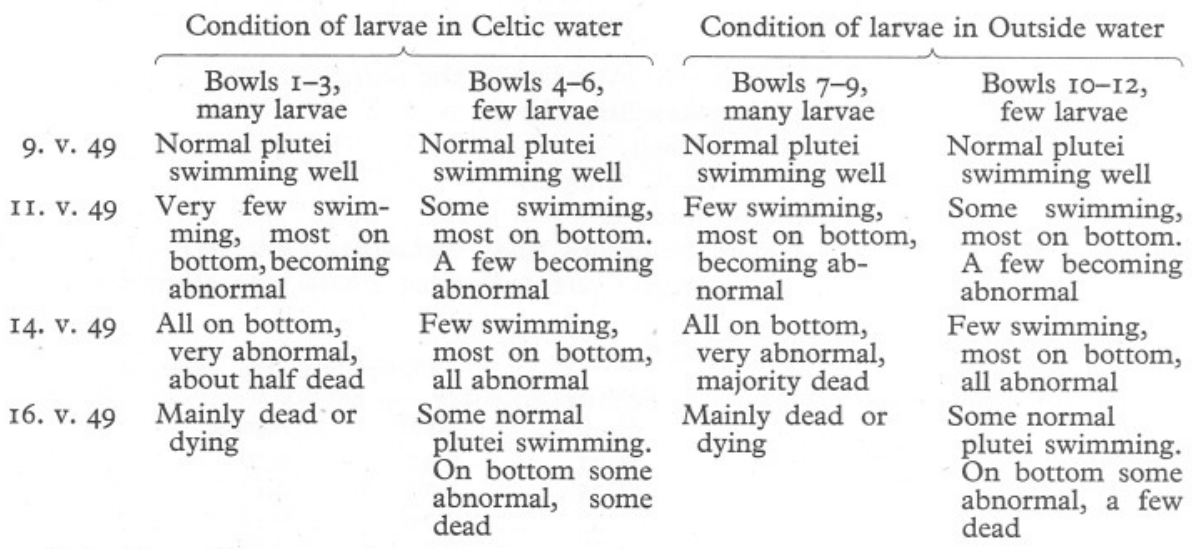

\section{Experiment 8A}

Celtic sea water collected from $20 \mathrm{~m}$. by means of the pump.

Position: station $64,50^{\circ} 33^{\prime}$ N., $8^{\circ} 51^{\prime}$ W., 25 miles west of Labadie Bank. Sounding: I $25 \mathrm{~m}$.

Date: 29. iv. 50. Time: OI.30 hr. G.M.T.

Ship: R.V. Sabella with Mr P. G. Corbin.

Conditions: wind force 4, sea slight.

Plankton: night haul, rich, abundant Sagitta elegans, two or three S. serratodentata, a few Limacina, Tomopteris, fairly numerous Euphausians. No sign of phytoplankton. Physical and chemical conditions:

\begin{tabular}{|c|c|c|c|c|c|c|c|}
\hline \multirow{2}{*}{$\begin{array}{l}\text { Depth } \\
\text { (m.) }\end{array}$} & \multirow{2}{*}{$\begin{array}{l}\text { Temp. } \\
\left({ }^{\circ} \mathrm{C} .\right)\end{array}$} & \multirow{2}{*}{$\underset{(\%)}{\text { Salinity }}$} & \multicolumn{3}{|c|}{ Phosphorus (mg.-atom $/ \mathrm{m}^{3}$ ) } & \multirow[b]{2}{*}{ Silicate } & \multirow{2}{*}{$\begin{array}{c}\text { Plant } \\
\text { pigments } \\
\text { units under } \\
\text { I m. } .^{2}\end{array}$} \\
\hline & & & Total & Inorganic & Organic & & \\
\hline 20 & $9 \cdot 78$ & $35 \cdot 19$ & $0.6 \mathrm{I}$ & 0.47 & 0.14 & $3 \cdot 3$ & - \\
\hline $\begin{array}{l}\text { Integral mean } \\
\text { of water colu }\end{array}$ & - & - & 0.65 & 0.49 & 0.16 & $3 \cdot 3$ & 0 \\
\hline
\end{tabular}

Outside sea water collected from sea surface with wooden bucket.

Position: E I, $50^{\circ} \mathrm{O2}^{\prime} \mathrm{N}$., $4^{\circ} 22^{\prime} \mathrm{W}$. Sounding: $74 \mathrm{~m}$.

Date: 3. v. 50 . Time: I2.30 hr. G.M.T.

Ship: M.F.V. Sula with Dr L. H. N. Cooper. 
Plankton: daylight haul, very sparse zooplankton except for abundant pilchard eggs. Phaeocystis very abundant.

Physical and chemical conditions:

\begin{tabular}{|c|c|c|c|c|c|}
\hline \multirow{2}{*}{$\begin{array}{l}\text { Depth } \\
\text { (m.) }\end{array}$} & \multirow{2}{*}{$\begin{array}{l}\text { Temp. } \\
\left({ }^{\circ} \mathrm{C} .\right)\end{array}$} & \multirow{2}{*}{$\begin{array}{c}\text { Salinity } \\
(\% \circ)\end{array}$} & \multicolumn{3}{|c|}{ Phosphorus (mg.-atom/m. ${ }^{3}$ ) } \\
\hline & & & Total & Inorganic & Organic \\
\hline o & 10.86 & $35 \cdot 14$ & 0.49 & 0.13 & 0.33 \\
\hline $\begin{array}{l}\text { Integral mean of } \\
\text { water column }\end{array}$ & - & - & 0.52 & 0.17 & 0.35 \\
\hline
\end{tabular}

The resources of total phosphorus were greater at the Celtic sea station but minimum production as assessed from organic phosphorus was less.

Two new, previously unused Berkefeld filter candles (both of same batch from maker), specially cleaned and sterilized by Mr F. A. J. Armstrong, were used for filtration.

\begin{tabular}{|c|c|c|c|}
\hline & $\begin{array}{l}\text { Condition of larvae } \\
\text { in Celtic water } \\
\text { (dishes I-5) }\end{array}$ & $\begin{array}{l}\text { Condition of larvae } \\
\text { in mixed water } \\
\text { (dishes 6-10) }\end{array}$ & $\begin{array}{l}\text { Condition of larvae } \\
\text { in Outside water } \\
\text { (dishes } 11-15 \text { ) }\end{array}$ \\
\hline 5. v. 50 & $\begin{array}{l}\text { Majority concentrating } \\
\text { near surface }\end{array}$ & $\begin{array}{l}\text { Majority concentrating } \\
\text { near surface }\end{array}$ & $\begin{array}{l}\text { Majority concentrating } \\
\text { near surface }\end{array}$ \\
\hline 8. v. 50 & $\begin{array}{l}\text { Most at surface, many } \\
\text { in mid-water, few on } \\
\text { bottom. Larvae } \\
\text { normal }\end{array}$ & $\begin{array}{l}\text { Many at surface, many } \\
\text { in mid-water, some on } \\
\text { bottom }\end{array}$ & $\begin{array}{l}\text { Some at surface, some } \\
\text { in mid-water, most on } \\
\text { bottom. Larvae } \\
\text { mainly abnormal }\end{array}$ \\
\hline 9. v. 50 & $\begin{array}{l}\text { All swimming with } \\
\text { concentration at sur- } \\
\text { face. Normal plutei, } \\
\text { abnormalities rare }\end{array}$ & $\begin{array}{l}\text { Many swimming with } \\
\text { slight concentration at } \\
\text { surface. Fair number } \\
\text { on bottom. Larvae } \\
\text { mainly normal }\end{array}$ & $\begin{array}{l}\text { Fair number swim- } \\
\text { ming in mid-water, } \\
\text { most on bottom. } \\
\text { Majority abnormal }\end{array}$ \\
\hline v. 50 & $\begin{array}{l}\text { About } 20 \% \text { swimming. } \\
\text { Larvae becoming ab- } \\
\text { normal, very few dead }\end{array}$ & $\begin{array}{l}\text { About } 20 \% \text { swimming. } \\
\text { Larvae fairly normal; } \\
\text { fair number dead }\end{array}$ & $\begin{array}{l}\text { Few swimming. } \\
\text { Majority abnormal, } \\
\text { many dead }\end{array}$ \\
\hline v. 50 & $\begin{array}{l}\text { Single dish. Some } \\
\text { swimming. Larvae } \\
\text { rather abnormal, } \\
\text { many dead }\end{array}$ & $\begin{array}{l}\text { Single dish. A few } \\
\text { living, abnormal. } \\
\text { Most dead }\end{array}$ & Single dish. All dead \\
\hline
\end{tabular}

Echinus esculentus fertilization made in Outside water on 5. v. 50. Three sets, each of five crystallizing dishes, used to test each kind of water and a mixture of both waters in equal proportion. Larvae were highly concentrated, there being several hundreds per dish.

Results are summarized in Table VIII A. They are positive in favour of Celtic water and the mixed water was nearly as good as the Celtic. After IO. v. 50 only one dish of each kind of water was retained.

Two dishes, one of Celtic and the other of Outside water, were photographed side by side on 9. v. 50 (Pl. II, fig. I). These dishes were typical of all the others. Larvae from both natural waters were photographed on 8. v. 50 (Pl. I, figs. 3, 4). 
Experiment 8B.

Particulars of waters and fertilization as for Exp. 8A. No mixed water used. Three dishes of each kind of water were on 6. v. 50 supplied with a few surface-swimming blastulae pipetted from the two beakers containing the original fertilization (see p. 5, describing method). On I2. v. 50 to one dish of each kind of water were added, for food, a few drops of a mixture of autotrophic flagellates from culture. This was repeated on I7. v. 50 .

Results are summarized in Table VIIIв. They are positive in favour of Celtic water. Larvae did badly in Outside water in spite of the low concentration. Fed larvae did a little better than unfed. Food did little to improve the

Table VIII B. Exp. 8B. Fertilization of ECHINUS ESCULENTUS MADE ON 5 May I950. Thin Cultures

Condition of larvae in Celtic water (dishes I6-I8)

6. v. 50 Most swimming near surface

8. v. 50 All in mid-water or at surface. Larvae normal

9. v. 50 All swimming well up. Normal plutei

10. v. 50 All swimming well up. Most plutei well developed

Dishes I6-I7

I2. v. 50 Most swimming
well, normal. A few slightly abnormal

$\begin{array}{clc}\text { I7. v. 50 } & \begin{array}{l}\text { Thin-armed } \\ \text { plutei swimming } \\ \text { well }\end{array} & \begin{array}{c}\text { Normal plutei } \\ \text { swimming } \\ \text { strongly }\end{array} \\ \text { 20. v. 50 } & \begin{array}{l}\text { Thin-armed } \\ \text { plutei swimming } \\ \text { well }\end{array} & \begin{array}{l}\text { Normal plutei, } \\ \text { half of them } \\ \text { swimming. A } \\ \text { few dead }\end{array}\end{array}$

25. v. 50 No change
Dish 18 - fed

All normal swimming strongly

Normal plutei swimming

Normal plutei, swimming. A few dead

$$
\begin{aligned}
& \text { Majority swim- } \\
& \text { ming, fairly } \\
& \text { normal plutei }
\end{aligned}
$$

Condition of larvae in Outside water (dishes I9-2I)

Most swimming near surface

Few at surface, most on bottom. Larvae mainly abnormal

Few swimming, most on bottom. Majority abnormal

Some swimming, most on bottom. Majority abnormal

Dishes 19-20 Dish 21 - fed

All on bottom, all All on bottom, abnormal majority abnormal

All on bottom, One or two swimall abnormal ming. All abnormal

All on bottom, One or two swimabnormal de- ming, one fairly generating. A normal pluteus. few dead Majority abnormal degenerating. A few more dead

All on bottom, One or two swimall abnormal ming. All abnormal, often degenerating

condition of the larvae in Outside water. The food was eaten, but it may not have been entirely suitable.

Experiment 9.

Particulars of waters as for Exp. 8A, but another portion in another pair of carboys used. The Berkefeld filter candles were cleaned and changed over, that used to filter Celtic water in Exps. 8A and B now being used to filter Outside water, and vice versa.

E. esculentus fertilization made in Outside water on Io. v. 50 and, as usual, immediately divided into halves and each washed off with one of the waters. 
After $\frac{3}{4} \mathrm{hr}$. it was noticed that most of the still undivided eggs were irregular, not normally rounded, inside the fertilization membrane, and this condition was more marked in Outside than in Celtic water. Two dishes of each kind of water were tested.

Results are summarized in Table IX. They are positive in favour of Celtic water. The difference was shown unusually early; this may have been due to over-ripeness of the eggs, almost all Echinus having spawned by this date, those few which had not usually showing histolysis of the ova. The female used for the experiment had only four ovaries. Another factor to be considered is the air temperature which was considerably higher than at any other time during the course of these Echinus experiments (both years). The temperature was high from I0. $\mathrm{v}$ to $\mathrm{I} 4 . \mathrm{v}$ ( $16-19^{\circ} \mathrm{C}$. outside in the shade at $\mathrm{IO}$ a.m., room temperatures were two or three degrees higher) and then dropped several degrees centigrade, remaining relatively cool until the end of the month.

TABle IX. Exp. 9. Fertilization of EChinus esculentus MADE ON IO MAY I950

\begin{tabular}{|c|c|c|}
\hline & $\begin{array}{c}\text { Condition of larvae in Celtic water } \\
\text { (dishes I-2) }\end{array}$ & $\begin{array}{c}\text { Condition of larvae in Outside water } \\
\text { (dishes } 3-4 \text { ) }\end{array}$ \\
\hline II. V. 50 & $\begin{array}{l}\text { Blastulae swimming strongly, many } \\
\text { at surface }\end{array}$ & Most on bottom, few swimming \\
\hline I2. v. 50 & $\begin{array}{l}\text { Many at surface, few on bottom. Few } \\
\text { abnormal, few dead }\end{array}$ & $\begin{array}{l}\text { Few at surface, many on bottom. } \\
\text { Abnormals and dead fairly numerous }\end{array}$ \\
\hline I4. v. 50 & $\begin{array}{l}\text { Few swimming; most on bottom ab- } \\
\text { normal; a few dead }\end{array}$ & $\begin{array}{l}\text { Few swimming, most on bottom, } \\
\text { abnormal, about } 50 \% \text { dead }\end{array}$ \\
\hline I6. v, 50 & $\begin{array}{l}\text { Large number swimming but ma- } \\
\text { jority on bottom. Arms being re- } \\
\text { generated }\end{array}$ & $\begin{array}{l}\text { Almost all dead. A very few living, } \\
\text { abnormal }\end{array}$ \\
\hline I8. v. 50 & $\begin{array}{l}\text { Large number swimming strongly, } \\
\text { majority on bottom. Further re- } \\
\text { generated, some almost normal. A } \\
\text { few degenerate, a few dead }\end{array}$ & All dead \\
\hline
\end{tabular}

One dish of each kind of water was photographed side by side on I6. v. 50 (Pl. II, fig. 2). Each dish was typical of all others in its series.

\section{Experiment Io.}

Particulars of waters as for Exp. 9. This experiment ran concurrently with the latter, a different pair of adults being used for the fertilization, which was made in Celtic water. The female appeared to be partially spawned. The fertilized eggs produced normal fertilization membranes, and cleavage was also normal. Five dishes of each kind of water were tested.

Results are summarized in Table X. They are positive in favour of Celtic water. At first, larvae were weaker than usual in both waters, due possibly to the high air temperatures I0. v-I4. v, or to over-ripe ova, or to both. Improvement in the Celtic water coincided with lower air temperatures from I5. v onwards. 


\section{Table X. Exp. io. Fertilization of Echinus esculentus MADE ON IO MAY I950}

Condition of larvae in Celtic water (dishes 5-9)

II. v. 50 Blastulae swimming up to surface

I2. v. 50 A few swimming up: majority on bottom, some abnormal

I4. v. 50 Most on bottom, a few dead

I5. v. 50 Some fairly normal plutei swimming well up. Most on bottom, shortarmed or armless

I7. v. 50 Many fairly normal plutei swimming, with some concentration at surface. Most on bottom, slightly abnormal
Condition of larvae in Outside water (dishes ro-r4)

Blastulae swimming up to surface

A few swimming up: majority on bottom, some abnormal

Most on bottom, many dead

None swimming, a large proportion dead. Living larvae very abnormal

A very few swimming; majority on bottom. All still living very abnormal

\section{Experiment with Sabellaria alveolata $(L$.}

The success of the early experiments with Ophelia and with Echinus made it desirable that a trial should be made of other species. So far only one other has been tried; this was Sabellaria alveolata which on I2. iv. 49 was collected at Duckpool, near Bude, on the north coast of Cornwall, where it is abundant.

\section{Experiment II.}

Particulars of waters as for Exps. 3-5.

A fertilization was made in Celtic water on I3.iv. 49. This was equally divided and washed off in both kinds of water in the usual way. Surface-swimming larvae were decanted into clean bowls on I4. iv. 49. One finger bowl of each kind of water was tested. For food, a few drops of a culture of an autotrophic flagellate was added to both bowls on I4. iv. 49 and again on 20. iv. 49 .

Table XI. Exp. II. Fertilization of SABELLARIA ALVEOLATA MADE ON I3 APRIL 1949

Condition of larvae in Celtic water

20. iv. 49 Very few abnormal larvae

25. iv. 49 Majority normal, fast swimming. Very few abnormal

27. iv. 49 Majority normal, fast swimming. Very few abnormal

3. v. 49 Many abnormal, many dead

Io. v. 49 Many abnormal, many dead, but some normal, though lethargic, larvae
Condition of larvae in Outside water Some larvae abnormal, losing bristles Many abnormal. All larvae swimming slowly

Many abnormal. All larvae swimming slowly

Many abnormal, many dead

Similar to Celtic water

Results are summarized in Table XI. They are positive in favour of Celtic water. At first larvae in both bowls were similar, but after a week some of these in Outside water were losing the long provisional bristles characteristic of this species (Wilson, 1929). On 25. iv. 49 a big proportion of these larvae were abnormal. They had few or no bristles, shrunken bodies, and were slow swimming. In Celtic water, on this date, there were very few abnormal larvae to be seen; almost all of them were quite normal and fast-swimming. After another week, however, both lots of larvae were in poor condition. They were 
too crowded for there to have been any possibility of normal growth through their long pelagic development.

\section{Other Experiments}

A few other experiments were undertaken; they may be mentioned briefly.

An experiment with Ophelia bicornis similar to those already described was begun 5 days later than Exp. 2, using waters from the same collections. This fertilization of Ophelia made on I7. vii. 48 gave only a relatively small number of larvae. Those in Celtic water did better than those in Outside water, but the difference was not as great as in the earlier experiment, and in neither water did the larvae do well. The fertilization may have been poor initially, or the Celtic water with longer storage was losing its health-imparting property.

Using the Outside water obtained at L 5 on 2. v. 49 (details as for Exp. 7), some tests were made to see if it could be improved by the addition of various substances. A fertilization of Echinus esculentus was made in this water on 20. v. 49 and distributed in equal quantity among a number of finger bowls. Addition of soil extract in the proportion used by Gross (1937) to two of the bowls did not improve matters, and the larvae after 5 days were in poorer condition than in three bowls of untreated water. At the suggestion of $\mathrm{Dr} \mathrm{H}$. W. Harvey other bowls were treated with vitamin $\mathrm{B}_{1}$ (aneurin hydrochloride), and another set with biotin in various minute proportions. These appeared to have no effect. In this experiment the larvae did rather better than in the same Outside water in Exp. 7, but there was no test of Celtic water with this particular fertilization.

The observation that larvae sometimes regenerated the larval arms led to an experiment to establish the fact more firmly. On 6. iv. 49 a small number of larvae with very short stumpy arms were picked out from one bowl of Celtic water and one of Outside water (bowls forming part of Exp. 5) and placed in new bowls of Celtic water and given autotrophic flagellates for food. On II. iv. 49 it was observed that a good proportion of these larvae had fairly long arms, and by 20. iv. 49 most of them had normal arms. At first the arms were thin and needle-like, but later were of normal thickness. The larvae transferred from Celtic water did rather better than those from Outside water where a higher proportion failed to regenerate any of the arms.

\section{Discussion}

In experiments of the character just described, one of the most fruitful sources of error would be concealed contamination. In spite of every effort to achieve complete cleanliness, and to treat both sides of an experiment alike, a small unobserved detail of procedure might bias one side more favourably than the other. The technique adopted has been carefully considered with this in mind.

If we take the 1950 experiments alone, it could be pointed out that whereas the Celtic water was collected from $20 \mathrm{~m}$. with a pump, the Outside water was 
obtained by another ship from the surface with a bucket. The original intention had been to collect both samples with the pump, but weather and other uncontrollable factors had made this impossible. Incidentally, when collecting with the pump the water was sucked through a hose and through the carboy to the pump so that water in the carboy had no contact with the pump itself. A thorough wash through was given before any water was actually taken. Similarly with the wooden bucket method of collection, great care was taken to wash out well the bucket and carboy before the latter was filled. The carboys were thoroughly cleaned in the chemical laboratory ashore, before being taken to sea. (For full details of the method of collecting water samples see Cooper, 195I.) Even so, the objection may be raised that the methods of collection for the I950 experiments were not the same for both waters. Criticism along these lines, however, can probably be discounted when it is remembered that for the I949 experiments both waters were collected with wooden buckets.

Another criticism, raised during the experiments, was the possibility of some form of contamination by the Berkefeld filter candles. It might be that one candle affected the water differently from the other. This criticism was met by changing over the filter candles so that the one previously used for Outside water was now used for Celtic water, and vice versa. This was done both in I 949 (see notes to Exps. 6 and 7) and in 1950 (see note to Exp. 9) and in both years, particularly in 1950, it is very evident that the results were unaffected by this procedure (Pl. II, figs. I, 2). Moreover, the pair of candles used in I950 was not the same as the pair used in 1949. There is no reason to continue to suspect the filter candles, although it will still be wise to change them over with each new experiment.

The technique used would result in a slight variation in the volume of water and number of larvae per test vessel in each experiment. The variation would, however, be very small and would not be biased in favour of either kind of water. Larvae behaved alike in all test vessels of water of one origin. The small variation in volume and number has therefore no significance. Moreover, consideration of Exp. 7, and comparison of Exp. 8A with 8B, shows that acceleration of the onset of abnormality and death is not unduly accelerated by crowding.

Apart from the experimental details just discussed and discounted no other possible sources of error have been discovered. Thus we conclude that the difference between the waters is real and natural. It should now be considered whether the difference is in any way related to seasonal changes in the plankton, for it is possible that past floras and faunas will have extracted or excreted substances, the absence or presence of which will affect developing larvae. Lucas (1949) has discussed the ecological significance of metabolites, some of them stimulating, others the reverse, in marine and other environments.

The sample of Celtic water which in Exp. 7 proved to be no better than Outside water was observed, before filtration, to contain abundant Phaeocystis. 
This colonial flagellate was also abundant, before filtration, in the Outside water used in Exps. 8 A, 8 B and 9. It was not, however, seen in other Outside water samples. It is just possible that it was responsible for the poor condition of the Celtic water used in Exp. 7, but in view of the fact that Outside water, whether it contained Phaeocystis or not, was always poor, such an interpretation must be regarded with suspicion. However, the possibility cannot be ruled out entirely.

Except for Phaeocystis there is no other correlation of poor water conditions with the observed plankton content, with the possible exception of the occasional abundance of pilchard eggs. It seems therefore more likely that the observed difference is due to something more fundamental, the presence or absence of traces of one or more elements or perhaps traces of organic materials. The results obtained by mixing equal quantities of the two waters (Exps. 5 and 8A) suggest that Celtic water contains something essential for normal development of some species which is lacking in Outside water. Other explanations of the effect of mixing may be possible, but this is perhaps the most reasonable assumption to take as a starting-point for investigation. The importance of various micro-constituents of sea water, especially organic substances and manganese, in the growth of phytoplankton has been emphasized in the work of Harvey (1947, I949, 1950); it is very probable that the health of zooplankton is likewise dependent on the presence of trace substances, though not necessarily the same substances, and that different species have different requirements.

The bodily forms of the unhealthy plutei (Pl. I, fig. 2) which developed in Outside water are certainly suggestive of a deficiency disease. They show analogous resemblances to plutei experimentally produced by workers concerned with the mechanics of sea-urchin development. With increasing age these abnormal larvae became more and more shrunken, unless they died first.

In the experiments there is evidence (see Exp. 6 and p. 15) that Celtic water deteriorates with storage in ordinary glass carboys at room temperature. Adsorption of the health-promoting factor by the glass is one of various possibilities.

Altogether, during two breeding seasons, eight distinct fertilizations of Echinus have been used to test comparatively Celtic water collected on three cruises, and Outside water collected on four separate occasions. In addition, there were separate collections of water for the tests with Ophelia; the Sabellaria tests used water collected for Echinus. Of the eight Echinus tests, six were positive in favour of the Celtic water and two were neutral. Possible reasons for the two latter have already been discussed above. The Ophelia and Sabellaria tests were all positive in favour of Celtic water. In all these experiments the only good rearings have been in Celtic water and all Outside water rearings have been bad. It does not follow, however, that Outside water is always bad. At present, the most that can be inferred is that 
good rearings are more likely to be obtained by using Celtic water than by using water from the Channel in the region of the Eddystone. So far, no comparative tests have been made with inshore water.

This is the first observation that has been made to show that the difference in bottom faunas from one region to another may be related to the ability, or otherwise, of larval stages to develop in the overlying water mass. For instance, Luidia ciliaris (Philippi) is at the present time infrequent off Plymouth where about eighteen years ago it was common, but it is known that its larvae are indicators of elegans water and were present in the area when it was covered with elegans water (Russell, I $936 b$, p. 597). Other species dependent to a greater or lesser extent on elegans water are likely to have been adversely affected when that water mass moved away from the area. Thus Munida bamffica (Pennant), formerly abundant on the Plymouth trawling grounds, is now at best exceedingly rare, while there has been a reduction in the abundance of Echinus esculentus itself which when needed in quantity has to be trawled more to the westward than formerly. Sabellaria alveolata, although still present at the mouth of the Erme estuary, also seems less common than it used to be. It must not be thought, however, that the fauna of the Plymouth area shows a general allround reduction; on the contrary, it is probably true to say that most species are as plentiful as ever, and some may even be more plentiful. It is evident that many animals find no difficulty in living and reproducing under water conditions that seem to affect some other species adversely. Nevertheless, it is possible that at least some of the former are invigorated by an elegans "environment, and that under laboratory conditions their larvae may succeed in elegans water when they will fail in that obtained from another water mass. Ophelia bicornis is an instance of a species thriving in a non-elegans environment, though there is no doubt that its larvae did better in the laboratory when kept in Celtic water (which in these experiments seemed always to have been elegans water) than in Outside water from the Eddystone region. It should be noted that Ophelia larvae have not been tested with the inshore estuarine water of their natural environment, which may well be more suitable for them than Outside water.

\section{SUMMARY}

Eggs and larvae of Echinus esculentus, Ophelia bicornis and Sabellaria alveolata developed abnormally, or were in poor health, in sea water collected from the English Channel in the region of the Eddystone, although in water collected from the Celtic sea development was generally normal and healthy. Experiments indicated that the Channel water lacked some unknown constituent, essential for healthy development of these species, present in the Celtic sea. The results accord with some of the hydrographical and biological changes in the area which have taken place within recent years. 


\section{REFERENCES}

Armstrong, F. A. J. \& Harvey, H. W., I950. The cycle of phosphorus in the waters of the English Channel. Fourn. Mar. Biol. Assoc., Vol. xxix, pp. I45-62.

Cooper, L. H. N., I938. Phosphate in the English Channel, 1933-8, with comparison with earlier years, I916 and 1923-32. Fourn. Mar. Biol. Assoc., Vol. xxiII, pp. I8I-95.

- I95I. Chemical properties of the sea water in the neighbourhood of the Labadie Bank. Fourn. Mar. Biol. Assoc., Vol. xxx, pp. 2I-6.

Cooper, L. H. N. \& VAUX, D., I949. Cascading over the continental slope of water from the Celtic sea. Fourn. Mar. Biol. Assoc., Vol. xxvin, pp. 719-50.

Gross, F., I937. Notes on the culture of some marine plankton organisms. Fourn. Mar. Biol. Assoc., Vol. xxI, pp. 753-68.

Harvey, H. W., I947. Manganese and the growth of phytoplankton. Fourn. Mar. Biol. Assoc., Vol. xxvi, pp. 562-79.

- 1949. On manganese in sea and fresh waters. Fourn. Mar. Biol. Assoc., Vol. xxvin,, pp. $155-64$.

- 1950. On the production of living matter in the sea off Plymouth. Fourn. Mar. Biol. Assoc., Vol. xxix, pp. 97-137.

LuCAS, C. E., I949. External metabolites and ecological adaptation. Symposia Soc. Exp. Biol., No. III, pp. 336-56.

RUSSELL, F. S., I935. On the value of certain plankton animals as indicators of water movements in the English Channel and North Sea. Fourn. Mar. Biol. Assoc., Vol. xx, pp. 309-32.

- $1936 \mathrm{a}$. Observations on the distribution of plankton animal indicators made on Col. E. T. Peel's yacht St George in the mouth of the English Channel, July, I935. fourn. Mar. Biol. Assoc., Vol. xx, pp. 507-22.

- $1936 b$. The seasonal abundance of the pelagic young of teleostean fishes in the Plymouth area. Part III. Fourn. Mar. Biol. Assoc., Vol. xx, pp. 595-604.

— I939. Hydrographical and biological conditions in the North Sea as indicated by plankton organisms. Fourn. Cons. Int. Explor. Mer, Vol. xIv, pp. I7I-92.

Wilson, D. P., I929. The larvae of the British sabellarians. Fourn. Mar. Biol. Assoc., Vol. XVI, pp. 22I-69. 


\section{EXPLANATION OF PLATES}

(All photographs on both plates are by electronic flash at about $\frac{1}{300 \overline{0}} \mathrm{sec}$.)

\section{Plate I}

Fig. I. Normal swimming plutei from Celtic water, Exp. 5. Photographed alive on 7. iv. 50 when 8 days old, $\times 43$.

Fig. 2. Abnormal swimming plutei from Outside water, Exp. 5. Photographed alive on 7. iv. 50 when 8 days old, $\times 43$. At this time no normal plutei were present in any of the Outside water dishes. Many lying on the bottom were in worse condition than these.

Fig. 3. Normal plutei from Celtic water, Exp. 8A. Larvae in Celtic water in Exp. 8B were indistinguishable from these. Photographed alive on 8. v. 50 when 3 days old, $\times 25$.

Fig. 4. Abnormal plutei from Outside water, Exp. 8A. Larvae in Outside water in Exp. 8B were indistinguishable from these. Photographed alive on 8 . v. 50 when 3 days old, $\times 25$.

\section{Plate II}

Fig. I. Typical dishes from Exp. 8A photographed on 9. v. 50 when the larvae were 4 days old. On the left is an Outside water dish with most of the larvae concentrated in a patch on the bottom, although a fair number are still swimming in mid-water. The other four Outside water dishes were similar. On the right is a Celtic water dish with all the larvae swimming well up. The other four Celtic water dishes were similar.

Fig. 2. Typical dishes from Exp. 9 photographed on I6. v. 50 when the larvae were 6 days old. The Berkefeld filter candles had been changed over since Exps. 8A and B (see p. I2). On the left is a Celtic water dish with many larvae swimming well up although some are resting on, or are close to, the bottom; few are dead. The other Celtic water dish was similar. On the right is an Outside water dish with almost all the larvae dead in a large patch on the bottom. The other Outside water dish was similar. 






